\title{
In situ measurements of the electrical conductivity of bismuth molybdate catalysts in operation for oxidative dehydrogenation of butene
}

\author{
Citation for published version (APA): \\ van Oeffelen, D. A. G., Hooff, van, J. H. C., \& Schuit, G. C. A. (1985). In situ measurements of the electrical \\ conductivity of bismuth molybdate catalysts in operation for oxidative dehydrogenation of butene. Journal of \\ Catalysis, 95(1), 84-100. https://doi.org/10.1016/0021-9517\%2885\%2990010-7, https://doi.org/10.1016/0021- \\ 9517(85)90010-7
}

DOI:

10.1016/0021-9517\%2885\%2990010-7

10.1016/0021-9517(85)90010-7

Document status and date:

Published: 01/01/1985

\section{Document Version:}

Publisher's PDF, also known as Version of Record (includes final page, issue and volume numbers)

\section{Please check the document version of this publication:}

- A submitted manuscript is the version of the article upon submission and before peer-review. There can be important differences between the submitted version and the official published version of record. People interested in the research are advised to contact the author for the final version of the publication, or visit the DOI to the publisher's website.

- The final author version and the galley proof are versions of the publication after peer review.

- The final published version features the final layout of the paper including the volume, issue and page numbers.

Link to publication

\footnotetext{
General rights

- You may freely distribute the URL identifying the publication in the public portal. follow below link for the End User Agreement:

www.tue.nl/taverne

\section{Take down policy}

If you believe that this document breaches copyright please contact us at:

openaccess@tue.nl

providing details and we will investigate your claim.
}

Copyright and moral rights for the publications made accessible in the public portal are retained by the authors and/or other copyright owners and it is a condition of accessing publications that users recognise and abide by the legal requirements associated with these rights.

- Users may download and print one copy of any publication from the public portal for the purpose of private study or research.

- You may not further distribute the material or use it for any profit-making activity or commercial gain

If the publication is distributed under the terms of Article $25 \mathrm{fa}$ of the Dutch Copyright Act, indicated by the "Taverne" license above, please 


\title{
In Situ Measurements of the Electrical Conductivity of Bismuth Molybdate Catalysts in Operation for Oxidative Dehydrogenation of Butene
}

\author{
D. A. G. van Oeffelen, ${ }^{*}$ J. H. C. van Hooff, ${ }^{*}$ and G. C. A. Schuit $\dagger$ \\ *Laboratory for Inorganic Chemistry and Catalysis, Eindhoven University of Technology, P.O. Box 513, \\ $5600 \mathrm{MB}$ Eindhoven, The Netherlands, and †Center for Catalytic Science and Technology, \\ Department of Chemical Engineering, University of Delaware, Newark, Delaware 1971I
}

Received February 21, 1984; revised March 23, 1985

\begin{abstract}
In situ measurement of electrical conductivities were performed on $\mathrm{MoO}_{3}, \mathrm{Bi}_{2} \mathbf{M o}_{2} \mathrm{O}_{9}$, and $\mathrm{Bi}_{2} \mathrm{MoO}_{6}$ (koechlinite), the latter either as such or doped with small amounts of $\mathrm{Mo}$ or $\mathrm{Bi}$; the reaction applied was the oxidative dehydrogenation of butene to butadiene. The reaction was performed in continuous flow or by pulsing butene over the catalyst, often followed by the addition of $\mathrm{O}_{2}$ pulses. The catalysts were characterized by surface area, XRD, and XPS. The latter measurements showed that surface $\mathrm{Bi} / \mathrm{Mo}$ ratios were often different from those in the bulk; reduction by butene at temperatures around $673 \mathrm{~K}$ sometimes led to considerable changes in the surface $\mathrm{Bi} / \mathrm{Mo}$ ratio that ran parallel with changes in activity. Pulsing butene in a He carrier stream over the catalyst strongly increased the electrical conductivity while pulsing $\mathrm{O}_{2}$ decreased it again; the conductivity is almost entirely located in the surface layers. The koechlinite-type catalysts, when heated in He, showed a considerably higher conductivity than the other catalysts. This is ascribed to a dissociation of $\mathrm{O}_{2}$ presumably from the $\mathrm{Bi}_{2} \mathrm{O}_{2}$ layers. Subsequent pulsing of butene first increased the conductivity but for catalysts with $\mathrm{Bi} / \mathrm{Mo}$ bulk ratios $>1$, the conductivities became constant while reduction continued. The first process is supposed to be connected with a stripping of the oxygen in the surface layer, the second with a migration of $\mathrm{O}^{2-}$ from bulk to surface and of electrons from surface to bulk. A model was presented for the surface band. (O) 1985 Academic Press, Inc.
\end{abstract}

\section{INTRODUCTION}

The essence of the redox mechanism as accepted for the catalytic oxidation of olefins over oxide catalysts, is a donation of protons and electrons by the hydrocarbon to the solid catalyst. The protons combine with oxygen atoms to form water thereby depleting the surface anion concentration; $\mathrm{O}_{2}$ molecules replenish surface anions by dissociative adsorption. The state of the electrons in the solid is not very well known and one might hope to obtain some information on this state by studying the electron mobility in an electric field, i.e., measuring the electrical conductivity of the catalyst. A well-known difficulty in analyzing the experimental conductivity data is given by the contribution to the overall conductivity of the migration of ions.
Several reports have appeared in literature covering studies about the electrical conductivity of bismuth molybdates.

Pluta $(1,2)$ investigated the conductivity of $\mathrm{MoO}_{3}, \mathrm{Bi}_{2} \mathrm{O}_{3}$, and bismuth molybdate $\left(\mathrm{Bi} / \mathrm{Mo}=0.7\right.$ on $\mathrm{SiO}_{2}$ carrier) in air, oxygen, and propene and at temperatures between 400 and $500^{\circ} \mathrm{C}$. Already during outgassing of the bismuth molybdate, changes were observed, which were ascribed to desorption of chemisorbed oxygen atoms. Contact with propene raised the conductivity, while air (or oxygen) restored it to its original value. The increase in conductivity during propene admission was ascribed to a reduction of the oxide, while the decrease after oxygen addition was considered to be caused by the reoxidation.

Peacock et al. (3) also investigated the conductivity of pressed disks of $\mathrm{Bi}_{2} \mathrm{O}_{3}$, 
$\mathrm{MoO}_{3}$, and bismuth molybdate $(\mathrm{Bi} / \mathrm{Mo}=$ 0.7 ) in propene and air (or oxygen) at $500^{\circ} \mathrm{C}$. By admitting propene to bismuth molybdate they observed a considerable increase in conductivity; this could be eliminated by subsequent admission of oxygen. They showed that the increase in conductivity was brought about by extensive reduction of the surface layers of the catalysts. Similarly, the decreases after oxygen admission had to be ascribed to reoxidation of the reduced surfaces. They were able to show that the bismuth molybdate catalyst was about $10 \%$ reduced when operating with mixtures of propene and oxygen under normal steady-state conditions. Furthermore they were able to determine the temperature dependence of the conductivity of the catalyst in oxidized and in partially reduced states. They showed that the energy gap decreased with increasing reduction. They concluded that the conductivity measurements can produce information about the reduction of the surface and perhaps a few subsurface layers, but do not furnish information about the oxidation states of the individual ions present in the surface.

Morrison (4) described the interaction of bismuth molybdates $(\mathrm{Bi} / \mathrm{Mo}=0.7)$ with oxygen and propene and the corresponding conductivity changes. At $T<275^{\circ} \mathrm{C}$ propene reacted only with what is assumed to be adsorbed oxygen, so that the conductivity after propene admission reaches a maximum. However, at $T>275^{\circ} \mathrm{C}$ propene reacted also with "irreversible oxygen," i.e., lattice oxygen, so that in this case the conductivity did not reach a maximum and reduction was continuous.

Our conductivity measurements on the bismuth molybdates differ from those mentioned before on the following points.

The experimental arrangements were as follows. We first determined activities of the various samples as a function of the temperature in continuous-flow modes when the reactants streamed through a bed of catalyst powder.

We then repeated the experiments in a reactor where a pellet was present so that the reactants streamed around the pellet; its electrical conductivity could then be measured either in AC or DC current. These experiments were not particularly informative; electrical conductivities were low and in the order of $10^{-6}-10^{-7}\left(\Omega^{-1} \mathrm{~cm}^{-1}\right)$ when no butene was present to increase somewhat when the olefin was added to the gas. It was then decided to use the method whereby pulses of butene and oxygen were injected into a He stream passing the pellet. The electrical conductivities were measured when the olefin pulse passed the pellet while its degree of conversion was then measured chromatographically. To obtain an impression of how the differences in flow patter, i.e., gas stream flowing along the pellet or through a bed of powdered catalyst, influenced the conversions, separate experiments with pulses flowing through a bed were also performed; for obvious reasons the latter experiment did not allow measurements of the conductivity.

\section{EXPERIMENTAL}

\section{Catalytic Activity Measurements}

When the butene oxidation was studied in a continuous-flow apparatus, a constant flow of a mixture of 1-butene and artificial air (ratio $\mathrm{C}_{4} \mathrm{H}_{8}: \mathrm{O}_{2}: \mathrm{He}=20: 20: 80$ ), passed through the catalyst bed $(400 \mathrm{mg}$, particle size $0.2-0.4 \mathrm{~mm}$ ) that was placed in a microreactor made of quartz glass. The reactor was heated by means of a heating wire, mounted on an aluminum tube. The temperature inside the catalyst bed was measured by a chromel alumel thermocouple [see Batist et al. (6)].

Samples of the product stream were analyzed gas chromatographically.

We used the following definitions:

$$
\begin{gathered}
\text { activity }=\frac{(\text { butenes })_{0}-(\text { butenes })_{T}}{(\text { butenes })_{0}} \cdot 100 \%, \\
\text { selectivity }=\frac{(\text { diene })}{(\text { diene })+\frac{1}{4}\left(\mathrm{CO}_{2}\right)} \cdot 100 \%,
\end{gathered}
$$




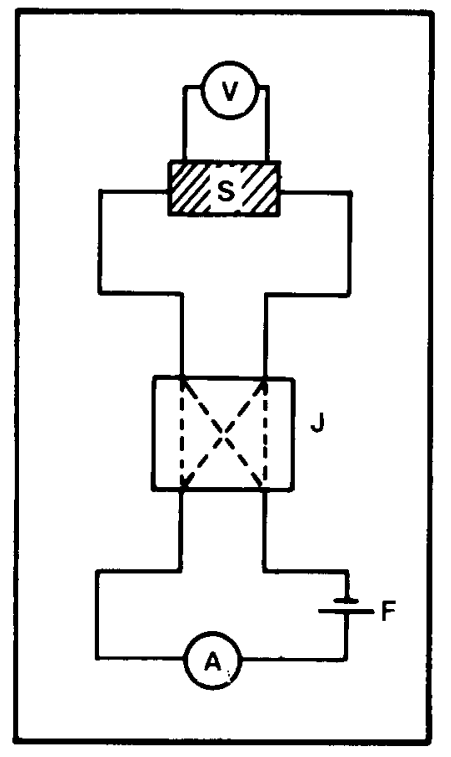

FIG. 1. Experimental set up for the electrical conductivity measurements. $S=$ sample, $F=$ constant voltage supply, $\mathrm{A}=$ multimeter, $\mathrm{V}=$ spot galvanometer, $\mathrm{J}=$ junction box.

in which

(butenes) $)_{0}=$ concentration of butenes before reaction,

(butenes) $)_{T}=$ concentration of butenes after reaction at temperature $T$,

(diene) $=$ concentration of butadiene,

$\left(\mathrm{CO}_{2}\right)=$ concentration of carbon dioxide.

For pulse experiments we used the same apparatus but the reactor was placed between sample valve and gas chromatographic column. The helium carrier gas was passing continuously over the catalyst; by means of a sample valve it was possible to pulse amounts of 1-butene over the catalyst with subsequent analysis of the reaction products. The volume of the pulse was $\mathbf{0 . 6}$ $\mathrm{cm}^{3}\left(25^{\circ} \mathrm{C}, 1 \mathrm{~atm}\right)$.

\section{Electrical Conductivity Measurements}

The electrical conductivity was measured on samples which were pressed to rectangular pellets under a pressure of 1000 $\mathrm{kg} / \mathrm{cm}^{2}$. The dimensions were about $15 \times 5$ $\times 5 \mathrm{~mm}$. The weight of the pellet was about $0.8 \mathrm{~g}$.

A four-probe technique was used, in which two of the electrodes served as current leads and the other two as voltage leads. Figure 1 gives a scheme of the experimental set up.

From current and voltage measurements the resistivity could be calculated. From the sample dimensions we could get a specific resistivity and an electrical conductivity:

$$
\sigma=\frac{1}{\rho}=\frac{L}{A} \cdot \frac{1}{R}
$$

in which

$L=$ distance between electrodes 3 and 4 (cm),

$A=$ cross-sectional area of pellet $\left(\mathrm{cm}^{2}\right)$,

$R=$ resistivity $(\Omega)$,

$\rho=$ specific resistivity $(\Omega \cdot \mathrm{cm})$,

$\sigma=$ electrical conductivity $\left(\Omega^{-1} \cdot \mathrm{cm}^{-1}\right)$.

The polarity could be changed to check charging effects.

The sample was spring-loaded between $P t$ contacts. Pt was used as electrode material; Pt leads were shielded by ceramic tubes. The electrode assembly was placed in a quartz glass tube, which could be supplied with different gases (Fig. 2). The outlet was connected with a gas chromatographic column, the same as used for the activity measurements. By means of a sample valve it was possible to carry out pulse experiments by pulsing 1-butene in a helium flow. The reactant gases were entering the tube directly below the catalyst pellet. The volume of the pulse was $0.9 \mathrm{~cm}^{3}$.

Because of the rather large volume of the tube it was not possible to get an ideal plug flow of the gases, thus preventing a good gas chromatographic analysis of the products. Freezing the reaction products for 15 min in a liquid nitrogen trap and subsequent quick heating to room temperature enabled us to get a reproducible analysis of the reaction products. 


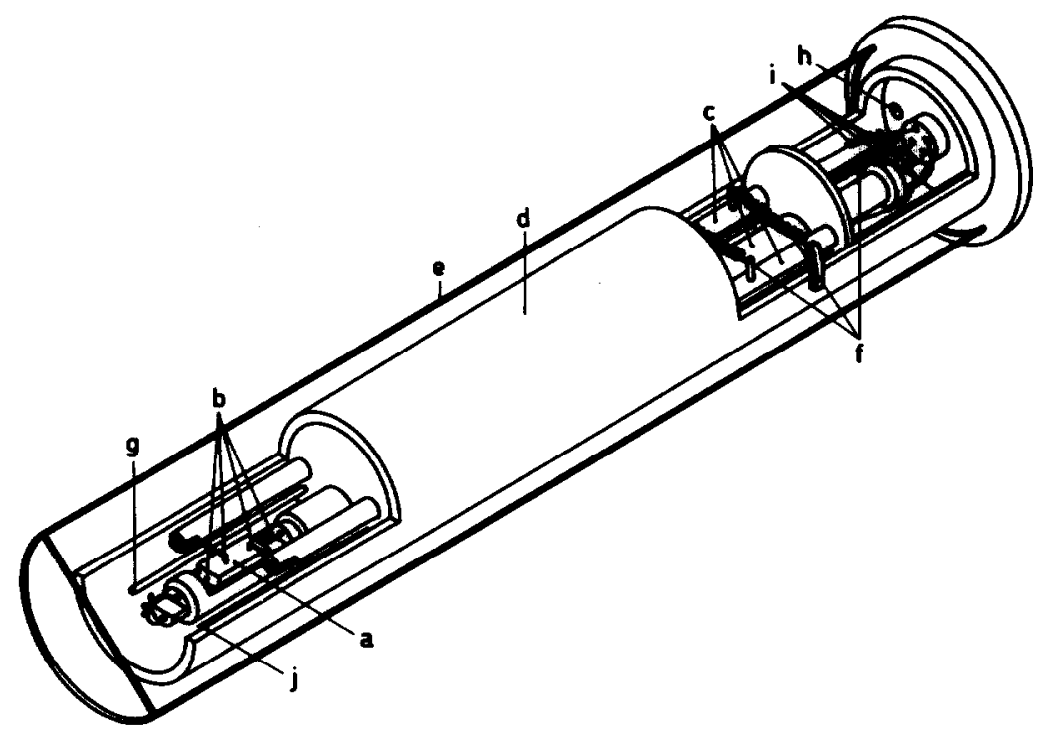

FIG. 2. Electrical conductivity cell and sample holder. $\mathrm{a}=$ Sample, $\mathrm{b}=$ electrodes, $\mathrm{c}=$ alumina ceramic tubes, $d=$ stainless-steel holder, $e=$ quartz glass tube, $f=$ springs, $g=$ inlet gases, $h=$ exit gases, $\mathrm{i}=$ electrode connections, $\mathrm{j}=$ thermocouple.

$X P S, X R D$, and SA Measurements

$X$-Ray photo electron spectroscopy. The apparatus used was at the Physical Chemistry Laboratory of the University of Groningen (The Netherlands). It was an AEI ES 200 spectrometer with $\mathrm{MgK} \alpha$ radiation $(1253.6 \mathrm{eV})$, with the power supply run at $16 \mathrm{kV}$ and $15 \mathrm{~mA}$. The spectra were collected using a PDP 8 computer and stored in a $32 \mathrm{~K}$ disk. The powdered samples were either stuck onto a piece of tape or pressed into a copper gauze. Sensitivity factors used were as given by Berthou and Jørgen$\operatorname{sen}(5)$.

$X$-Ray diffraction. We used a Philips PW 1120 spectrometer with $\mathrm{CuK} \alpha$ radiation and Ni filter.

Surface area measurements. These were performed with an areameter of Ströhlein, which is based on the single-point BET method using nitrogen as adsorbate.

\section{Preparation of the Catalysts}

The preparations were carried out with the following chemicals: basic bismuth ni- trate $\mathrm{BiONO}_{3}$ (Merck), powdered molybdic acid (BHD), ammonium heptamolybdate $\left(\mathrm{NH}_{4}\right)_{6} \mathrm{Mo}_{7} \mathrm{O}_{24} \cdot \mathrm{H}_{2} \mathrm{O}$ (Merck), bismuth nitrate $\mathrm{Bi}\left(\mathrm{NO}_{3}\right)_{3} \cdot 5 \mathrm{H}_{2} \mathrm{O}$ (Merck).

$\mathrm{Bi}_{2} \mathrm{O}_{3}$ was prepared by heating basic bismuth nitrate, containing $79.94 \mathrm{wt} \% \mathrm{Bi}_{2} \mathrm{O}_{3}$ at $520^{\circ} \mathrm{C}$ for $10 \mathrm{~h}$ to give $\alpha \mathrm{Bi}_{2} \mathrm{O}_{3}$ (Sample A).

$\mathrm{MoO}_{3}$ was prepared by heating molybdic acid, containing $88.98 \mathrm{wt} \% \mathrm{MoO}_{3}$ at $500^{\circ} \mathrm{C}$ for $4 \mathrm{~h}$ (Sample B).

$\mathrm{Bi}_{2} \mathrm{MoO}_{6}$ was prepared according to the slurry method of Batist (6): $16.177 \mathrm{~g}$ molybdic acid $\left(0.1 \mathrm{~mol} \mathrm{MoO}_{3}\right)$ and $58.289 \mathrm{~g}$ basic bismuth nitrate $\left(0.1 \mathrm{~mol} \mathrm{Bi}_{2} \mathrm{O}_{3}\right)$ were added to 1 liter boiling water. To the slurry was added a $4-\mathrm{cm}^{3}$ volume of concentrated nitric acid, after which the reaction was started. The slurry was vigorously stirred. After $12 \mathrm{~h}$ of reaction the yellow colored mass was filtered off, dried at $120^{\circ} \mathrm{C}$ for 16 $h$, and calcined at $500^{\circ} \mathrm{C}$ for $2 \mathrm{~h}$. The reaction could be carried out quantitatively as was shown by examining the obtained weight (Sample C).

$\mathrm{Bi}_{2} \mathrm{Mo}_{1.02} \mathrm{O}_{6.06}$ : The same method was used as for $\mathrm{Bi}_{2} \mathrm{MoO}_{6}$, except that we used 
$16.500 \mathrm{~g}$ molybdic acid (0.102 $\left.\mathrm{mol} \mathrm{MoO}_{3}\right)$. Here again the reaction was quantitative (Sample D).

$\mathrm{Bi}_{2.04} \mathrm{Mo}_{1} \mathrm{O}_{6.06}$ : Again a slurry method was used, starting with $16.177 \mathrm{~g}$ molybdic acid $\left(0.1 \mathrm{~mol} \mathrm{MoO}_{3}\right)$ and $59.204 \mathrm{~g}$ basic bismuth nitrate $\left(0.102 \mathrm{~mol} \mathrm{Bi}_{2} \mathrm{O}_{3}\right)$. The molybdic acid was first dissolved in aqueous ammonia. After $18 \mathrm{~h}$ of stirring and boiling the mass was filtered off, dried at $120^{\circ} \mathrm{C}$ for 16 $h$, and calcined at $500^{\circ} \mathrm{C}$ for $2 \mathrm{~h}$ (Sample $\mathrm{E}$ ). This preparation also yielded stoichiometric amounts as could be shown by weight analysis.

$\mathrm{Bi}_{2} \mathrm{Mo}_{2} \mathrm{O}_{9}$ : To $24.253 \mathrm{~g} \mathrm{Bi}\left(\mathrm{NO}_{3}\right)_{3} \cdot 5 \mathrm{H}_{2} \mathrm{O}$ $\left(0.025 \mathrm{~mol} \mathrm{Bi}_{2} \mathrm{O}_{3}\right)$ was added $13 \mathrm{~cm}^{3}$ concentrated $\mathrm{HNO}_{3}$ and dissolved in $100 \mathrm{ml}$ water; $8.827 \mathrm{~g}\left(\mathrm{NH}_{4}\right)_{6} \mathrm{Mo}_{7} \mathrm{O}_{24} \cdot 4 \mathrm{H}_{2} \mathrm{O}(0.05 \mathrm{~mol}$ $\mathrm{MoO}_{3}$ ) dissolved in $100 \mathrm{ml}$ water was added to the first solution with stirring. By adding aqueous ammonia the final $\mathrm{pH}$ was adjusted to 4 . Meanwhile the solutions were cooled in ice baths. The white precipitate was filtered off, dried at $120^{\circ} \mathrm{C}$ for $16 \mathrm{~h}$, and calcined at $500^{\circ} \mathrm{C}$ for $2 \mathrm{~h}$. This procedure yielded a stoichiometric sample as checked by weight analysis (Sample F).

$\mathrm{Bi}_{2} \mathrm{Mo}_{3} \mathrm{O}_{12}: 14.577 \mathrm{~g}$ basic bismuth nitrate $\left(0.015 \mathrm{~mol} \mathrm{Bi}_{2} \mathrm{O}_{3}\right)$ and molybdic acid $\left(0.075 \mathrm{~mol} \mathrm{MoO}_{3}\right)$ were brought into 1 liter water. The slurry was heated and stirred for $30 \mathrm{~h}$, during which time the color remained white. After filtration, drying at $120^{\circ} \mathrm{C}$ for $16 \mathrm{~h}$, and calcining for $2 \mathrm{~h}$ at $480^{\circ} \mathrm{C}$, the resultant material contained the stoichiometric amounts of bismuth and molybdenum as was checked by weight analysis (Sample G).

\section{RESULTS}

\section{Activities and Selectivities}

All the catalysts except A and B were tested for their activity and selectivity in the oxidative dehydrogenation of 1-butene under continuous flow. Conditions used were $400 \mathrm{mg}$ catalyst, total gas flow 120 $\mathrm{cm}^{3} / \mathrm{min}, \mathrm{C}_{4} \mathrm{H}_{8}: \mathrm{O}_{2}: \mathrm{He}=20: 20: 80$ (the results are given in Table 1 ).
The sample $\mathrm{Bi}_{2.04} \mathrm{MoO}_{6.06}$ was totally inactive over the sample temperature range investigated $\left(380-440^{\circ} \mathrm{C}\right)$.

The sample $\mathrm{Bi}_{2} \mathrm{Mo}_{1.02} \mathrm{O}_{6.06}$ showed a very high activity at temperatures higher than $420^{\circ} \mathrm{C}$, whereas the sample $\mathrm{Bi}_{2} \mathrm{MoO}_{6}$ had already a high activity at $380^{\circ} \mathrm{C}$, but this latter catalyst showed a considerably lower selectivity.

The catalyst $\mathrm{Bi}_{2} \mathrm{Mo}_{2} \mathrm{O}_{9}$ showed fairly high activity and a very high selectivity. The sample $\mathrm{Bi}_{2} \mathrm{Mo}_{3} \mathrm{O}_{12}$ prepared had low activity and high selectivity.

At $440^{\circ} \mathrm{C}$ the order of activity per unit of weight was: $\mathrm{Bi}_{2} \mathrm{Mo}_{1.02} \mathrm{O}_{6.06}>\mathrm{Bi}_{2} \mathrm{MoO}_{6}$ $>\mathrm{Bi}_{2} \mathrm{Mo}_{2} \mathrm{O}_{9} \gg \mathrm{Bi}_{2} \mathrm{Mo}_{3} \mathrm{O}_{12}>\mathrm{Bi}_{2.04} \mathrm{MoO}_{6.06}$.

The order of selectivity at $440^{\circ} \mathrm{C}$ was: $\mathrm{Bi}_{2}$ $\mathrm{Mo}_{2} \mathrm{O}_{9}=\mathrm{Bi}_{2} \mathrm{Mo}_{3} \mathrm{O}_{12}=\mathrm{Bi}_{2} \mathrm{Mo}_{1.02} \mathrm{O}_{6.06}>\mathrm{Bi}_{2}$ $\mathrm{MoO}_{6}$.

The inactive $\mathrm{Bi}_{2.04} \mathrm{MoO}_{6.06}$ became reactivated after adding $\mathrm{MoO}_{3}$. This was accomplished by taking $375 \mathrm{mg} \mathrm{Bi}_{2.04} \mathrm{MoO}_{6.06}$ and adding $25 \mathrm{mg} \mathrm{MoO}_{3}$, corresponding to about $25 \mathrm{~mol} \%$ Mo extra. After $30 \mathrm{~min}$ at $T$ $=440^{\circ} \mathrm{C}$ in the reactor, this mixture exhibited an activity of $59 \%$ and a selectivity of $89.5 \%$. At the end of this reaction time we could observe an appreciable amount of $\mathrm{Bi}_{2}$ $\mathrm{Mo}_{3} \mathrm{O}_{12}$ to be present, as shown by the infrared spectrum [bands at 950,930 , and 900 $\mathrm{cm}^{-1}$, which are attributed to the $2 / 3 \mathrm{com}$ pound (6)].

It was also possible to activate the $\mathrm{Bi}_{2.04}$ $\mathrm{MoO}_{6.06}$ sample by addition of an amount of a $\mathrm{Bi}_{2} \mathrm{Mo}_{3} \mathrm{O}_{12}$ sample with low activity.

The mixing of $300 \mathrm{mg} \mathrm{Bi} \mathrm{Bi}_{2.04} \mathrm{MoO}_{6.06}$ and $100 \mathrm{mg} \mathrm{Bi} 2 \mathrm{Mo}_{3} \mathrm{O}_{12}$ after $30 \mathrm{~min}$ in the reactor gave a catalyst with an activity of $47 \%$ and a selectivity of $89 \%$ at $440^{\circ} \mathrm{C}$.

\section{XPS Measurements}

We used the values of Berthou and Jørgensen (5) for the elemental sensitivities of $\mathrm{Bi}(4 \mathrm{f})=4.3, \mathrm{Mo}(3 \mathrm{~d})=1.6, \mathrm{O}(1 \mathrm{~s})=0.6$, and as reference $\mathrm{C}(1 \mathrm{~s})=2.85 \mathrm{eV}$. Table 2 lists the binding energies (standardized) and intensities for the catalysts given before. Table 3 compares the bismuth-molybdenum ratios for bulk compound with the ob- 
TABLE 1

Comparison of Conversions for Various Bi Molybdate Catalysts in Different Flow Situations

\begin{tabular}{|c|c|c|c|c|c|c|c|c|}
\hline \multirow[t]{3}{*}{ Catalyst $^{a}$} & \multirow{2}{*}{\multicolumn{2}{|c|}{$\begin{array}{c}\text { Catalyst com- } \\
\text { position } \\
\text { (Bi/Mo ratio) }\end{array}$}} & \multirow{3}{*}{$\begin{array}{c}\text { Reaction } \\
\text { temp. } \\
\left({ }^{\circ} \mathrm{C}\right)\end{array}$} & \multicolumn{5}{|c|}{ Butene conversion (\%) } \\
\hline & & & & \multirow{2}{*}{$\begin{array}{l}\text { Continuous } \\
\text { flow }\end{array}$} & \multicolumn{2}{|c|}{ Pulse method I } & \multicolumn{2}{|c|}{ Pulse method II } \\
\hline & Bulk & Surface & & & Pulse I & Pulse $(n)^{b}$ & Pulse 1 & Pulse $(n)^{b}$ \\
\hline E, 10.7 & 2.04 & 2.27 & $\begin{array}{l}350 \\
400 \\
450\end{array}$ & $\begin{array}{l}0 \\
0 \\
0\end{array}$ & $\begin{array}{l}0 \\
0 \\
3\end{array}$ & $\begin{array}{c}0 \\
14(8) \\
42(4)\end{array}$ & $\begin{array}{r}1 \\
3 \\
32\end{array}$ & $\begin{array}{l}17(5) \\
39(5)\end{array}$ \\
\hline C, 7.9 & 2.00 & 2.11 & $\begin{array}{l}350 \\
400 \\
450\end{array}$ & $\begin{array}{l}79^{c} \\
79 \\
83\end{array}$ & & & $\begin{array}{r}3 \\
40 \\
48\end{array}$ & $\begin{array}{c}13(5) \\
\text { All lower } \\
\text { All lower }\end{array}$ \\
\hline $\mathrm{D}, 7.3$ & 1.96 & 1.78 & $\begin{array}{l}350 \\
400 \\
450\end{array}$ & $\begin{array}{r}<26 \\
54 \\
95\end{array}$ & $\begin{array}{l}25 \\
44 \\
45\end{array}$ & $\begin{array}{c}\text { All lower } \\
\text { All lower } \\
50(2)\end{array}$ & $\begin{array}{l}23 \\
33 \\
42\end{array}$ & $\begin{array}{l}\text { All lower } \\
\text { All lower } \\
\text { All lower }\end{array}$ \\
\hline F, 4.3 & 1.00 & 0.93 & $\begin{array}{l}350 \\
400 \\
450\end{array}$ & $\begin{array}{l}<9 \\
31 \\
72\end{array}$ & $\begin{array}{l}18 \\
24 \\
40\end{array}$ & $58(9)$ & $\begin{array}{l}17 \\
26 \\
36\end{array}$ & \\
\hline $\mathrm{G}, 2.3$ & 0.67 & 0.70 & $\begin{array}{l}350 \\
400 \\
450\end{array}$ & $\begin{array}{r}<18 \\
<18 \\
18\end{array}$ & $\begin{array}{l}12 \\
20 \\
30\end{array}$ & $\begin{array}{l}23(5) \\
51(5)\end{array}$ & $\begin{array}{r}4 \\
10 \\
17\end{array}$ & \\
\hline
\end{tabular}

a Symbol and surface area (in $\mathrm{m}^{2} / \mathrm{g}$ ).

b Pulse $(n)=$ highest conversion at pulse $n$.

c Selectivity $=84 \%$, all others $\geq 95 \%$.

served XPS values for its surface. Figure 3 some powdered samples on tape. A shoulshows bismuth and molybdenum signals for der can be observed at higher binding ener$\mathrm{Bi}_{2} \mathrm{MoO}_{6}$ and Fig. 4 gives oxygen signals for gies; the low BE belongs to lattice oxygen.

TABLE 2

XPS Data: Binding Energy Values (eV) and Intensities (Int.) of Bi, Mo, and O Signals for the Various Catalysts

\begin{tabular}{|c|c|c|c|c|c|c|}
\hline \multirow[t]{2}{*}{ Sample } & \multicolumn{2}{|c|}{$\mathrm{Bi} \mathbf{4 f}$} & \multicolumn{2}{|c|}{ Mo 3d } & \multicolumn{2}{|c|}{ O 1s } \\
\hline & b.e. (eV) & Int. & b.e. (eV) & Int. & b.e. $(\mathrm{eV})$ & Int. \\
\hline \multirow[t]{2}{*}{$\mathrm{Bi}_{2,04} \mathrm{MoO}_{6.06}$} & 159.3 & 8.38 & 232.6 & 3.73 & 530.0 & 17.41 \\
\hline & 164.6 & & 235.7 & & 531.7 (sh) & \\
\hline \multirow[t]{2}{*}{$\mathrm{Bi}_{2} \mathbf{M o}_{1.02} \mathrm{O}_{6.06}$} & 159.5 & 10.65 & 232.7 & 6.03 & 530.3 & 25.75 \\
\hline & 164.9 & & 235.9 & & 532.1 (sh) & \\
\hline \multirow[t]{2}{*}{$\mathrm{Bi}_{2} \mathrm{MoO}_{6}$} & 159.8 & 131.7 & 233.0 & 62.4 & 530.6 & 295 \\
\hline & 165.1 & & 236.2 & & & \\
\hline \multirow[t]{2}{*}{$\mathrm{Bi}_{2} \mathrm{MO}_{2} \mathrm{O}_{9}$} & 160.0 & 28.46 & 233.0 & 30.68 & 530.8 & 126.7 \\
\hline & 165.5 & & 236.0 & & & \\
\hline \multirow{2}{*}{$\mathrm{Bi}_{2} \mathrm{MO}_{3} \mathrm{O}_{12}$} & 159.9 & 3.169 & 233.2 & 4.557 & 530.7 & 14.96 \\
\hline & 165.4 & & 236.1 & & & \\
\hline \multirow{2}{*}{$\begin{array}{l}\mathrm{Bi}_{2.04} \mathrm{MoO}_{6.06} \\
\text { (after activation) }\end{array}$} & 159.3 & 166.76 & 232.6 & 151.3 & 530 & 403.4 \\
\hline & 164.6 & & 235.7 & & & \\
\hline
\end{tabular}


TABLE 3

Comparison of the Calculated Bismuth-Molybdenum Bulk Ratios with the Observed Values from XPS Experiments

\begin{tabular}{lll}
\hline \multicolumn{1}{c}{ Sample } & Calc. & \multicolumn{1}{c}{ XPS } \\
\hline $\mathrm{Bi}_{2} \mathrm{Mo}_{1.02} \mathrm{O}_{6.06}$ & 1.96 & 1.767 \\
$\mathrm{Bi}_{2.04} \mathrm{MoO}_{6.06}$ & 2.04 & 2.245 \\
$\mathrm{Bi}_{2} \mathrm{MoO}_{6}$ & 2.00 & 2.11 \\
$\mathrm{Bi}_{2} \mathrm{Mo}_{2} \mathrm{O}_{9}$ & 1.00 & 0.928 \\
$\mathrm{Bi}_{2} \mathrm{Mo}_{3} \mathrm{O}_{12}$ & 0.67 & 0.695 \\
$\mathrm{Bi}_{2.04} \mathrm{MoO}_{6.06}$ & & 1.10 \\
$\quad$ (after activation) & & \\
\hline
\end{tabular}

Pressing in $\mathrm{Cu}$ gauze showed the high $\mathrm{BE}$ signal only as broadening.

\section{Pulse Experiments}

We performed pulse experiments by pulsing $0.6 \mathrm{~cm}^{3}$ of 1-butene over the powdered sample at different temperatures. Figure 5 shows the result for the catalyst $\mathrm{Bi}_{2} \mathrm{Mo}_{1.02} \mathrm{O}_{6.06}$. The conversion of butene per pulse decreased after the first pulse. At $450^{\circ} \mathrm{C}$ a small increase was observed for the second pulse, but subsequently there again was a decrease in conversion. A completely different behavior was shown by the catalyst $\mathrm{Bi}_{2.04} \mathrm{MoO}_{6.06}$ (Fig. 6). At $400^{\circ} \mathrm{C}$ there was no conversion during the first three pulses, but subsequently the activity increased, to reach a maximum whereafter it

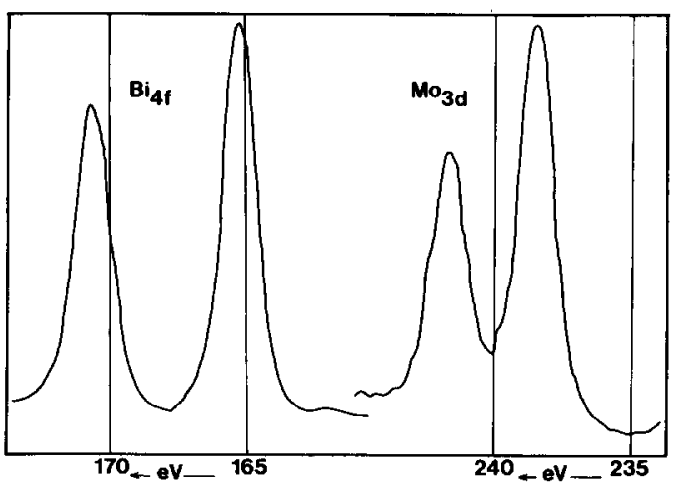

FIg. 3. $\mathrm{Bi}$ 4f and $\mathrm{Mo} 3 \mathrm{~d}$ XPS signals for $\mathrm{Bi}_{2} \mathrm{MoO}_{6}$.

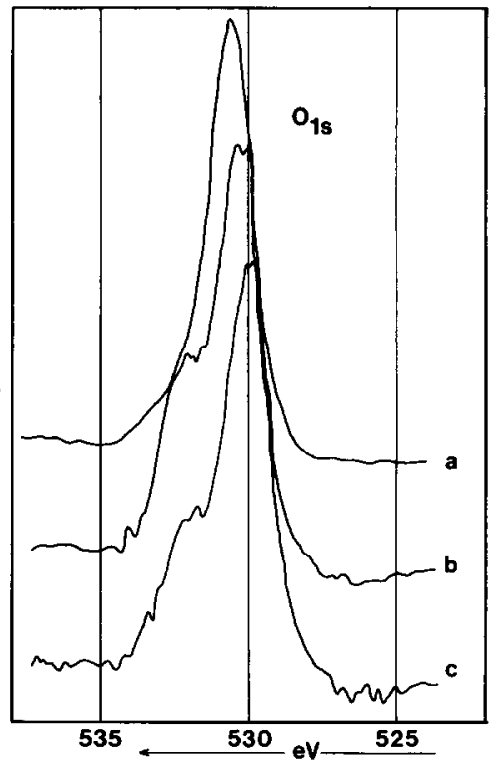

FIG. 4. O $1 \mathrm{~s}$ XPS signals for $\mathrm{Bi}_{2} \mathrm{MoO}_{6}$ (b), $\mathrm{Bi}_{2} \mathrm{Mo}_{1.02}$ $\mathrm{O}_{6.06}$ (a), and $\mathrm{Bi}_{2.04} \mathrm{MoO}_{6.06}$ (c) (powered sample mounted on tape).

decreased again, as observed for the first catalyst. After an intermediate reoxidation, the conversion at $450^{\circ} \mathrm{C}$ started again at a low level, but rose very quickly; it reached its maximum value at the fourth pulse.

During this activation process not only did the conversion increase, but the selectivity also became higher. After activation by reduction at $450^{\circ} \mathrm{C}$ the sample $\mathrm{Bi}_{2.04} \mathrm{Mo}$

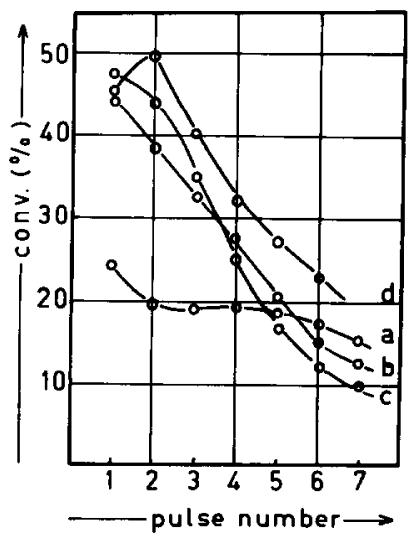

FIG. 5. Conversion of 1-butene during pulse experiments on $\mathrm{Bi}_{2} \mathrm{Mo}_{1.02} \mathrm{O}_{6.06}$ at 350 (a), 400 (b), 425 (c), and $450^{\circ} \mathrm{C}$ (d). 


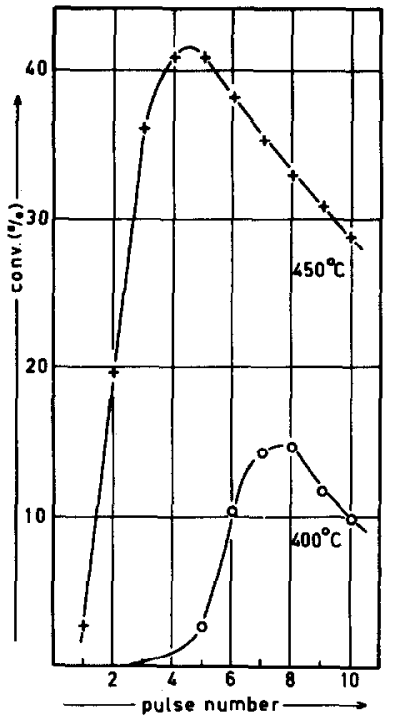

Fig. 6. Conversion of 1-butene during pulse experiments on $\mathrm{Bi}_{2.04} \mathrm{MoO}_{6.06}$ at 400 and $450^{\circ} \mathrm{C}$.

$\mathrm{O}_{6.06}$ was measured in XPS (Tables 2 and 3). The calculated $\mathrm{Bi} / \mathrm{Mo}$ ratio was now 1.10; compared to the former value of 2.27 this represents a major change, indicating that a considerable cation migration occurred during the activation process.

The catalysts $\mathrm{Bi}_{2} \mathrm{Mo}_{2} \mathrm{O}_{9}$ and $\mathrm{Bi}_{2} \mathrm{Mo}_{3} \mathrm{O}_{12}$ showed other characteristics. At 350 and $400^{\circ} \mathrm{C}$ a more or less constant level of conversion was observed. While at $450^{\circ} \mathrm{C}$ the conversion even increased during the first pulses; catalyst $\mathrm{Bi}_{2} \mathrm{Mo}_{2} \mathrm{O}_{9}$ reached the maximum value only after 10 pulses. It could be shown that during this reduction process the catalyst decomposed; an X-ray diagram taken after the reduction indicated an appreciable amount of $\mathrm{Bi}_{2} \mathrm{MoO}_{6}$ to be present. A survey of the conversions is given in Table 1 .

\section{Electrical Conductivity Measurements}

The measurements performed can be divided into three groups:

(a) Measurement of the temperature dependence of the conductivity in the oxidized state. From these measurements an overall activation energy for conduction can be calculated. (b) Measurement of conduction after admission of pulses of 1-butene (reduction) at different temperatures, together with the amount of butene converted at the same temperature (simultaneous measurement of conduction and conversion).

(c) Measurement of conduction and conversion after a reoxidation.

\section{Temperature Dependence of the \\ Conductivity under Air and He}

For this purpose we examined two of our samples, i.e., $\mathrm{Bi}_{2} \mathrm{Mo}_{1.02} \mathrm{O}_{6.06}$ and $\mathrm{Bi}_{2.04} \mathrm{Mo}$ $\mathrm{O}_{6.06}$, the active and the inactive sample, in the temperature range $350-500^{\circ} \mathrm{C}$. The measurements were carried out in air. The measured values of conductivity can be analyzed using the formula

$$
\sigma_{(T)}=\sigma_{0} \cdot \exp \left(\frac{E}{-k T}\right)
$$

Plotting $\log \sigma$ vs $\frac{1}{T}$ gave results as plotted in Fig. 7, for the active and the inactive sample. The active sample had much lower activation energy $(0.8 \mathrm{eV})$ than the inactive sample $(1.97 \mathrm{eV})$.

When we carried out the temperature dependence measurements in a helium atmosphere instead of air, we obtained different results. The initial activation energy for both active and inactive samples were much lower than under air, viz. 0.45 and

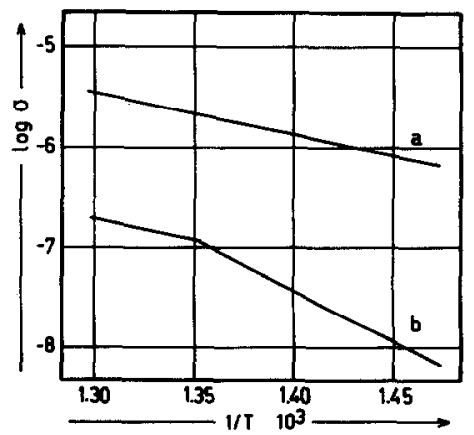

FIG. 7. Temperature dependence of the electrical conductivity of $\mathrm{Bi}_{2} \mathrm{Mo}_{1.02} \mathrm{O}_{6.06}$ (a) and $\mathrm{Bi}_{2.04} \mathrm{MoO}_{6.06}$ (b) in air. 
TABLE 4

The Activation Energy $E$ (in $\mathrm{eV}$ ) of the Electrical Conductivity for Samples D and E after Repeated Heating and Cooling in a Helium Stream

\begin{tabular}{lcccc}
\hline & \multicolumn{4}{c}{ Heating-cooling cycle } \\
\cline { 2 - 5 } & 1 & 2 & 3 & 4 \\
\hline $\mathrm{Bi}_{2} \mathrm{Mo}_{1.02} \mathrm{O}_{6.06}$ & 0.45 & 0.46 & 0.67 & 0.81 \\
$\mathrm{Bi}_{2.04} \mathrm{MoO}_{6.06}$ & 1.02 & 1.10 & 0.87 & 0.79 \\
\hline
\end{tabular}

$1.02 \mathrm{eV}$. After several heating-cooling periods the activation energies for active and inactive sample appeared to reach the same value (Table 4).

The time dependence of the conductivity under reducing conditions (propene $5 \mathrm{~cm}^{3 /}$ min) at $T=400^{\circ} \mathrm{C}$ again demonstrated a marked difference between the two samples. The active sample gave an immediate rise in conductivity, while the inactive sample had a much slower increase.

After several minutes of reduction with propene the conductivity appeared to ap- proach the conductivity of the active sample.

\section{Electrical Conductivity after Pulsing 1-Butene}

Conductivity and conversion were now measured simultaneously. The time between the successive pulses of butene was fixed at $25 \mathrm{~min}$ because of time requirements for analyzing the reaction products.

Figure 8 gives an example $\left(\mathrm{Bi}_{2} \mathrm{MoO}_{6}\right)$ of the changes in conductivity with increasing number of butene pulses for three different temperatures. In general the conductivity increased with the number of pulses passed over the catalyst. It is noteworthy, however, that between pulses a decrease of the conductivity could be observed. This decrease was typical for all measurements.

In order to avoid complicated drawings, the following figures will show only the maxima in conductivity after each pulse (compare Fig. 8b with a).

Figures 9-14 show conductivity and conversion values at 350,400 , and $450^{\circ} \mathrm{C}$ for,
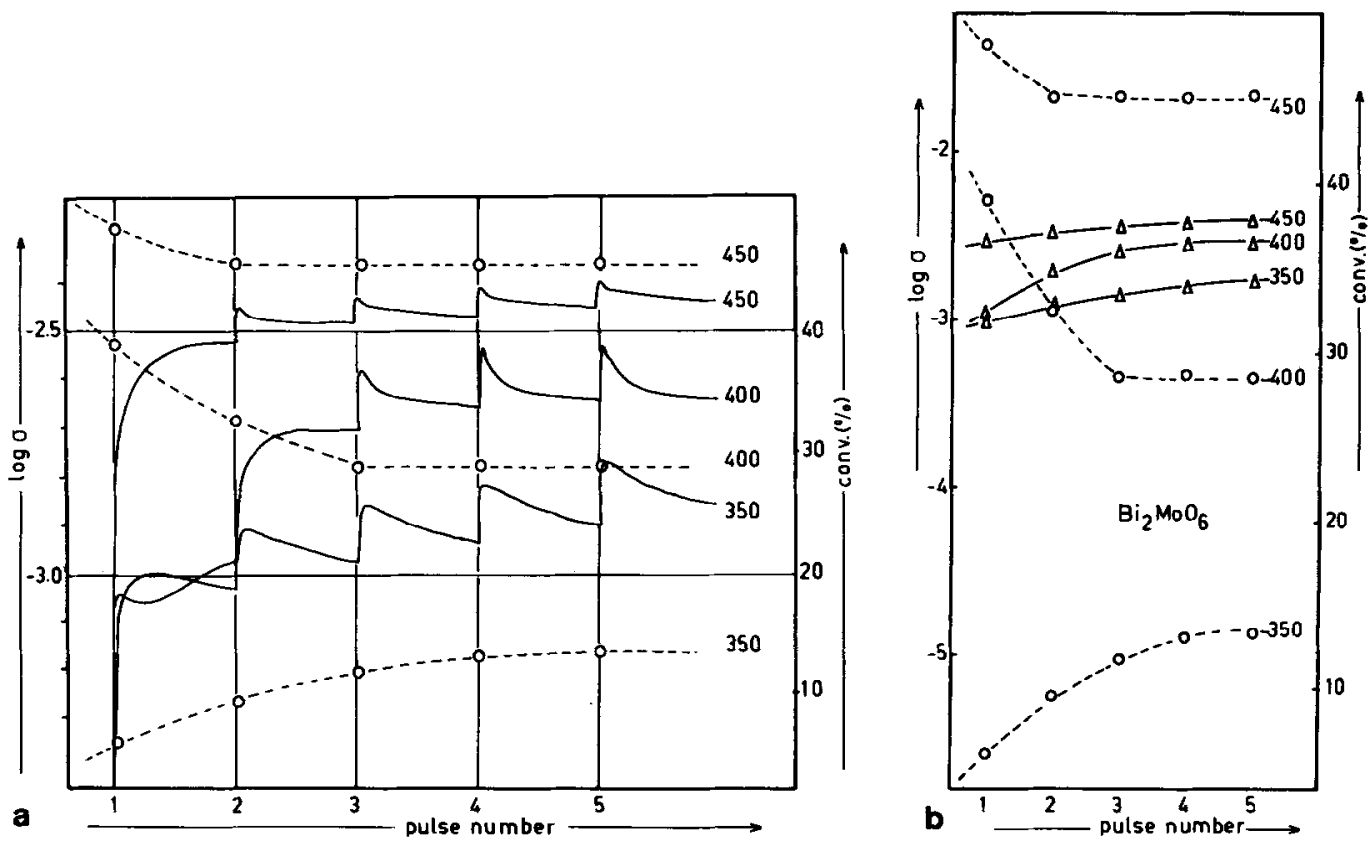

Fig. 8. Conversion of 1-butene $(O)$ and electrical conductivity $(\triangle)$ during pulse reduction of $\mathrm{Bi}_{2} \mathrm{Mo}$ $\mathrm{O}_{6}$ at 350,400 , and $450^{\circ} \mathrm{C}$. (a) Detailed picture of the changes in conductivity. (b) Maxima of conductivity after each pulse. 


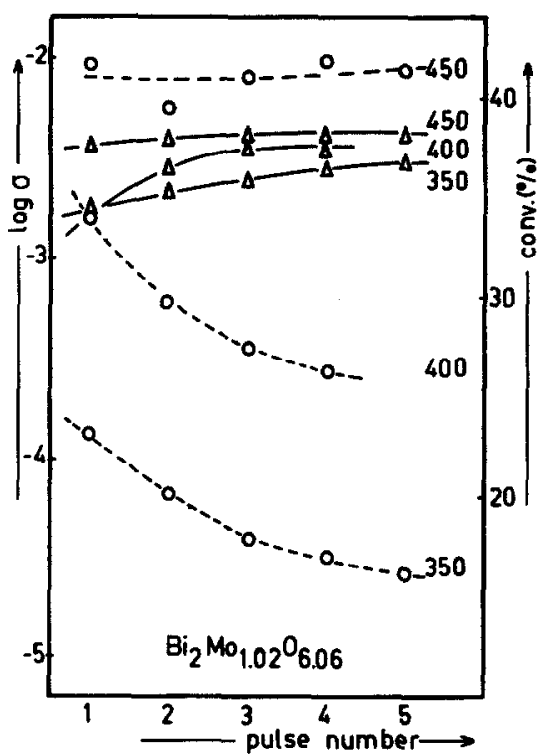

Fig. 9. Conversion of 1-butene (O) and electrical conductivity $(\triangle)$ during pulse reduction of $\mathrm{Bi}_{2} \mathrm{Mo}_{1.02}$ $\mathrm{O}_{6.06}$ at 350,400 , and $450^{\circ} \mathrm{C}$.

respectively, $\mathrm{Bi}_{2} \mathrm{Mo}_{1.02} \mathrm{O}_{6.06}, \mathrm{Bi}_{2.04} \mathrm{MoO}_{6.06}$, $\mathrm{Bi}_{2} \mathrm{Mo}_{2} \mathrm{O}_{9}, \mathrm{Bi}_{2} \mathrm{Mo}_{3} \mathrm{O}_{12}, \mathrm{MoO}_{3}$, and $\mathrm{Bi}_{2} \mathrm{O}_{3}$. Figure 9 shows that $\mathrm{Bi}_{2} \mathrm{Mo}_{1.02} \mathrm{O}_{6.06}$ already had a fairly high conductivity and a high conversion at $350^{\circ} \mathrm{C}(\log \sigma=-2.8$ resp. $\eta$ $=0.23$ after the first pulse with $\eta$ the fractional conversion). During further reduction the conductivity increased somewhat, but already after a few pulses a maximum value was reached. At $450^{\circ} \mathrm{C}$ there was hardly any change both in conductivity and conversion. This sample $\mathrm{Bi}_{2} \mathrm{Mo}_{1.02} \mathrm{O}_{6.06}$ showed the highest level of conduction of all our catalysts (highest value $\log \sigma=$ -2.4). Figure $8 \mathrm{~b}$ shows that $\mathrm{Bi}_{2} \mathrm{MoO}_{6}$ had a similar behavior as the former. The conductivity values were at a slightly lower level (maximum $\log \sigma=-2.45$ at $450^{\circ} \mathrm{C}$ ), but the conversion values were even a little higher.

Figure 10 shows some remarkable features. The sample $\mathrm{Bi}_{2.04} \mathrm{MoO}_{6.06}$ had a very low level of conversion at $350^{\circ} \mathrm{C}$; also the conductivity was relatively low compared to the former koechlinite samples $(\log \sigma=$ -4). At $400^{\circ} \mathrm{C}$ after two pulses of butene the conversion increased considerably and at the same time the conductivity arrived at a much higher level. At $450^{\circ} \mathrm{C}$ the conversion reached almost the same level as for the active catalysts; again the conductivity followed this trend and became as high as the value of the conductivity for the sample $\mathrm{Bi}_{2} \mathrm{Mo}_{1.02} \mathrm{O}_{6.06}$. After the runs at $450^{\circ} \mathrm{C}$, the temperature was lowered to $400^{\circ} \mathrm{C}$ and again butene pulses were given; there was now no initial period and from the first pulse on, the sample showed a high conversion.

The samples $\mathrm{Bi}_{2} \mathrm{Mo}_{2} \mathrm{O}_{9}$ and $\mathrm{Bi}_{2} \mathrm{Mo}_{3} \mathrm{O}_{12}$ showed in principle the same behavior as the $\mathrm{Bi}_{2} \mathbf{M o}_{1.02} \mathrm{O}_{6.06}$ sample although the conductivity level was lower (maximum $\log \sigma$ $=-4$ for $\mathrm{Bi}_{2} \mathrm{Mo}_{2} \mathrm{O}_{9}$ and $\log \sigma=-4.5$ for $\mathrm{Bi}_{2}$ $\mathrm{Mo}_{3} \mathrm{O}_{12}$ ) (Figs. 11 and 12). Figure 13 shows the situation for $\mathrm{MoO}_{3}$ which had a very low conversion and a low conductivity level $(\log \sigma=-6)$.

No conductivity could be measured for bismuth oxide at temperatures below

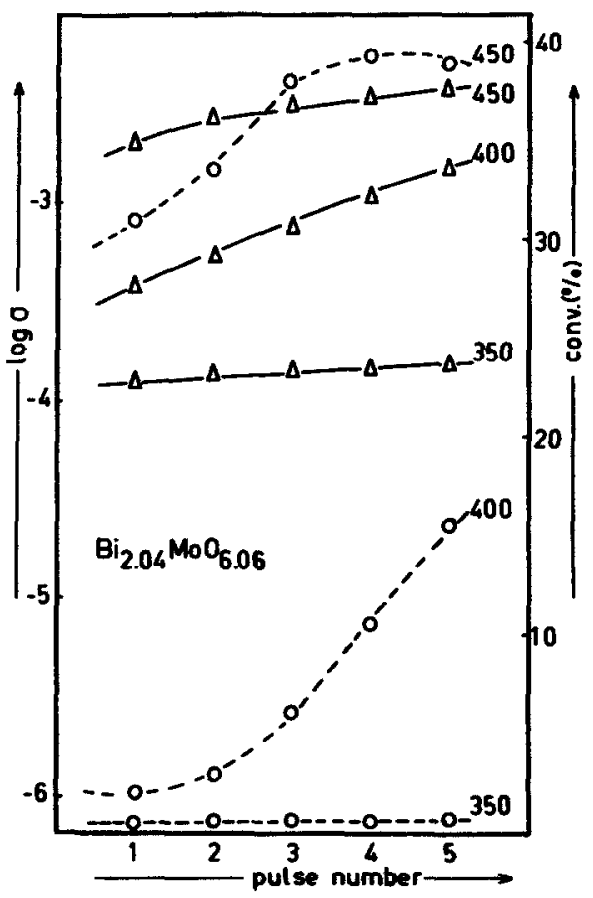

Fig. 10. Conversion of 1-butene $(O)$ and electrical conductivity $(\triangle)$ during pulse reduction of $\mathrm{Bi}_{2.04} \mathrm{Mo}$ $\mathrm{O}_{6.06}$ at 350,400 , and $450^{\circ} \mathrm{C}$. 


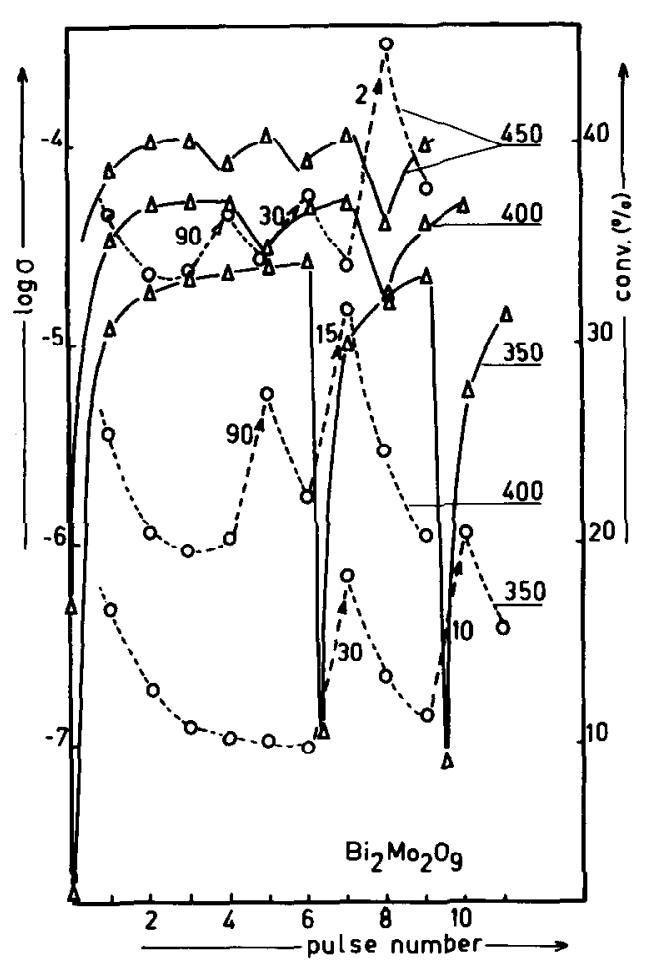

FIG. 11. Conversion of 1-butene $(O)$ and electrical conductivity $(\triangle)$ during pulse reduction and oxidation of $\mathrm{Bi}_{2} \mathrm{Mo}_{2} \mathrm{O}_{9}$ at 350,400 , and $450^{\circ} \mathrm{C}$. The numbers indicate the time intervals (in minutes) between an oxygen pulse and the next butene pulse.

$500^{\circ} \mathrm{C}$. Reduction lowered the conductivity at $500^{\circ} \mathrm{C}$ (Fig. 14) and reoxidation increased it again. This is completely opposite to the behavior of the bismuth molybdates. The difference can be explained by assuming that $\mathrm{Bi}_{2} \mathrm{O}_{3}$ is a p-type semiconductor while the molybdates are n-type semiconductors.

\section{Intermittent Reoxidation}

The foregoing experiments showed that the conductivity increased by reduction while simultaneously the fractional conversion decreased. The question is now how do conductivity and conversion behave after an intermittent oxidation pulse?

The method chosen was to dose an oxygen pulse at a certain moment after passage of a butene pulse and subsequently apply a new butene pulse. The time between oxygen pulse and second butene pulse was to

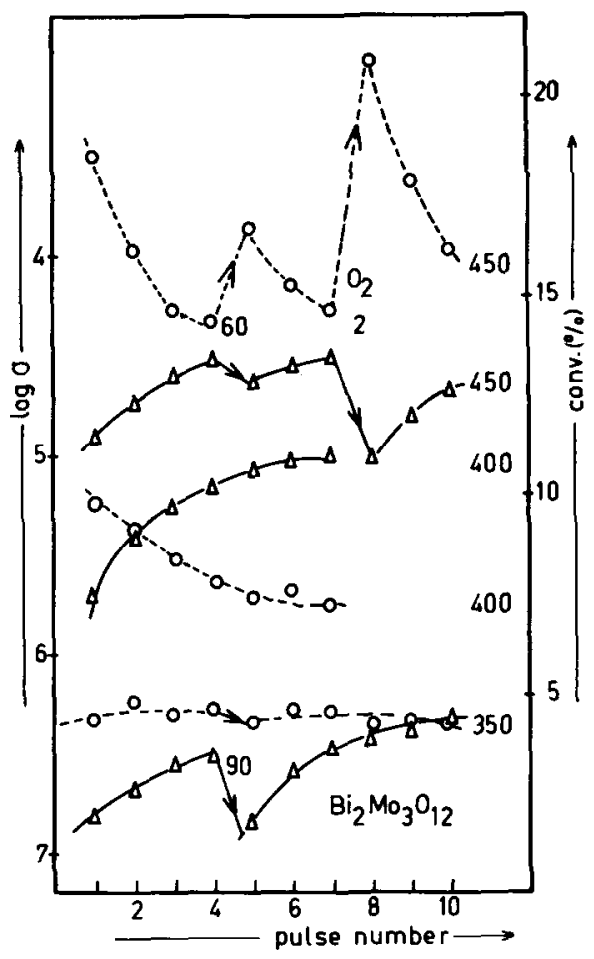

Fig. 12. Conversion of 1-butene $(O)$ and electrical conductivity $(\triangle)$ during pulse reduction of $\mathrm{Bi}_{2} \mathrm{Mo}_{3} \mathrm{O}_{12}$ at 350,400 , and $450^{\circ} \mathrm{C}$.

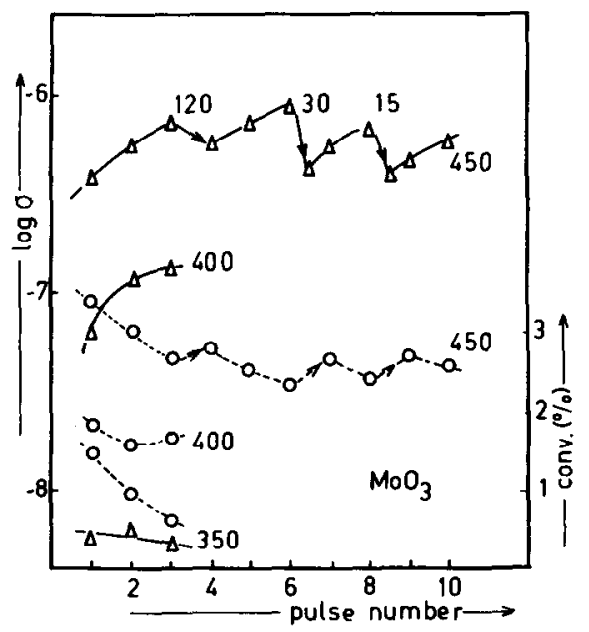

FIG. 13. Conversion of 1-butene $(O)$ and electrical conductivity $(\triangle)$ during pulse reduction and oxidation of $\mathrm{MoO}_{3}$ at 350,400 , and $450^{\circ} \mathrm{C}$. The numbers indicate the time intervals (in minutes) between an oxygen pulse and the next butene pulse. 


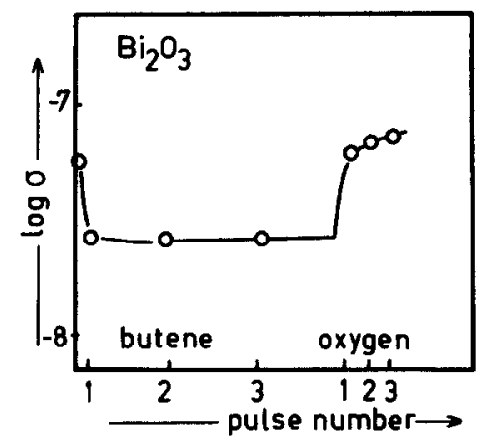

FIG. 14. Electrical conductivity of $\mathrm{Bi}_{2} \mathrm{O}_{3}$ at $500^{\circ} \mathrm{C}$ during 1-butene and oxygen pulses.

be varied. During the series of pulses there always remained a helium flow over the catalyst.

The scenario of the experiments was as follows.

(a) A series of butene pulses was fed to the reactor similarly as before (time intervals of $25 \mathrm{~min}$ ),

(b) an oxygen pulse was given,

(c) after $t=t_{1}$ a new butene pulse followed,

(d) a new series of butene pulses were added to arrive at the same situation as after the first series,

(e) again an oxygen pulse was added, and

(f) after $t=t_{2}$ a new butene pulse followed; the time differences $t_{1}$ and $t_{2}$ were varied.

Figure 15 shows the conductivity and conversion values during these experiments for the $\mathrm{Bi}_{2} \mathrm{Mo}_{1.02} \mathrm{O}_{6.06}$ sample. After reoxidation the conductivity became much lower. Most remarkable is the fact that conversion after reoxidation was dependent on the time between the oxygen pulse and the next butene pulse, i.e., the time during which the oxygen can do its reoxidizing work.

A short time results in a high conversion, while a long time gives a lower conversion, although this is still higher than the conversion with the first butene pulse. Reoxidation experiments were also carried out with the $\mathrm{Bi}_{2} \mathrm{Mo}_{2} \mathrm{O}_{9}$ (Fig. 11) and $\mathrm{Bi}_{2} \mathrm{Mo}_{3} \mathrm{O}_{12}$ (Fig. 12) with similar results as given above.
Another type of experiment was performed with $\mathrm{Bi}_{2} \mathrm{Mo}_{3} \mathrm{O}_{12}$. We examined the influence of the reoxidation during longer periods under helium. At $450^{\circ} \mathrm{C}$ after the fourth butene pulse we kept the catalyst for $1 \mathrm{~h}$ in a helium atmosphere. The next butene pulse showed a high conversion, while the conductivity during the intermediate period had decreased somewhat.

With $\mathrm{MoO}_{3}$ (Fig. 13) little changes were observed during reoxidation apart from a considerable decline in selectivity. This decrease in selectivity after a reoxidation pulse was also observed for the samples $\mathbf{B i}_{2}$ $\mathrm{Mo}_{1.02} \mathrm{O}_{6.01}$ and $\mathrm{Bi}_{2} \mathrm{Mo}_{3} \mathrm{O}_{12}$ although to a lesser degree.

\section{Some Additional Pulse Experiments}

The catalyst $\mathrm{Bi}_{2} \mathrm{Mo}_{1.02} \mathrm{O}_{6.06}$ was used to study the conductivity under reaction conditions by giving pulses of mixtures of oxygen and butene at $T=400^{\circ} \mathrm{C}$.

Figure 16 gives the influence of the ratio $r$ $=$ (butene) $/($ butene + oxygen) on conductivity and conversion. It shows that the conductivity is lower the more oxygen is present in the pulse while the fractional conversion is higher for greater oxygen contents. The selectivity of the reaction increases with higher butene ratios.

The variation of the amount of butene

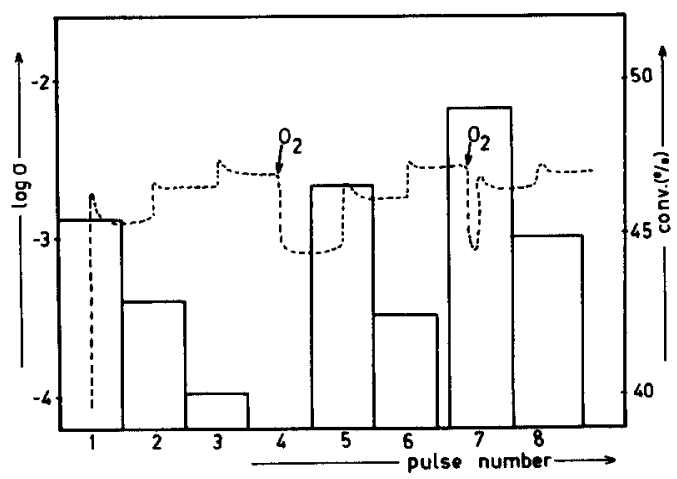

FIG. 15. Conversion of 1-butene $(O)$ and electrical conductivity $(\triangle)$ during pulse reduction and oxidation of $\mathrm{Bi}_{2} \mathrm{Mo}_{1.02} \mathrm{O}_{6.06}$ at $400^{\circ} \mathrm{C}$ with different time intervals between an oxygen pulse and the next butene pulse. 


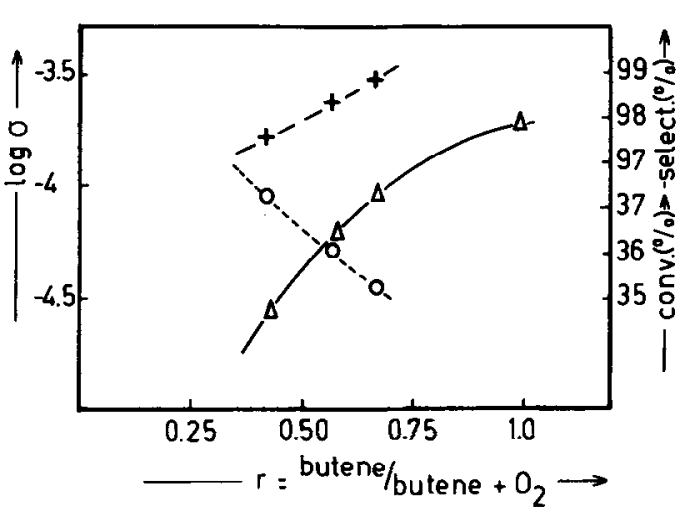

FIs. 16. Electrical conductivity $(\triangle)$, conversion of 1-butene $(O)$, and selectivity $(+)$ during pulses of butene-oxygen mixtures with variable composition on $\mathrm{Bi}_{2} \mathrm{Mo}_{1.02} \mathrm{O}_{6.06}$ at $400^{\circ} \mathrm{C}$.

added per single pulse was studied for $\mathrm{Bi}_{2}$ $\mathrm{Mo}_{2} \mathrm{O}_{9}$ at $450^{\circ} \mathrm{C}$ (Fig. 17), i.e., a situation in which the use of one pulse of the habitually applied size, i.e., $0.9 \mathrm{~cm}^{3}$ immediately gave a maximum conductivity that did not vary further with additional pulses. By varying the amount of butene delivered per first pulse after complete reoxidation it was tried to determine how much butene was necessary to arrive at the maximum level. Two loops were used for this purpose while moreover the butene content could be varied still further by dilution with helium. It is seen that amounts in the order of half those normally added sufficed to obtain maximal conductivity. It should be stressed that this could not be due to complete reduction of the catalyst as seen by the amount of butene converted that was still rising.

\section{DISCUSSION}

The reduction of an oxidic catalyst starts at its surface and will proceed to the interior by diffusion of oxygen anions from the bulk to the exterior. As a measure of the amount reduced per unit of surface we introduce the variable $\Sigma \eta_{p} / S$ where $\eta_{p}$ is the fractional conversion of pulse $p, \Sigma \eta_{p}$ the sum of the conversions of $p$ pulses and $S$ is the surface of the sample. Further on we shall abbreviate this to $\Sigma / S$, the definition of the degree of reduction.

It is helpful to estimate the maximal $\Sigma / S$ value for the reduction of a surface layer. Consider a layer comparable to the $\left(\mathrm{Bi}_{2}\right.$ $\left.\mathrm{O}_{2}\right) \mathrm{O}$ or the $\left(\mathrm{MoO}_{2}\right) \mathrm{O}$ layers in the bulk of $y$ $\mathrm{Bi}_{2} \mathrm{MoO}_{6}$ (koechlinite). Such a layer has about $2 \times 10^{19}$ oxygens $/ \mathrm{m}^{2}$; if we assume that $\mathrm{Mo}^{4+}$ and zero valent $\mathrm{Bi}$ represent the ultimate degree of reduction for $\left(\mathrm{MoO}_{2}\right) \mathrm{O}$ and $\left(\mathrm{Bi}_{2} \mathrm{O}_{2}\right) \mathrm{O}$, the maximal degree of reduction shall be between 33 and $100 \%$, and the number of oxygens removed between 0.6 and $2 \times 10^{19} / \mathrm{m}^{2}$. For pulses of $0.9 \mathrm{~cm}^{3}$ (containing $2.25 \times 10^{19}$ butene molecules), the maximal $\Sigma / S$ should be between 0.27 and 0.9 . Because in our experiments $\Sigma / S$ never surpassed a value of 0.5 , our results appear typically relevant for an incipient reduction of the catalyst's outer layers.

The experiments shown in Figs. 8a to 13 become more relevant when electrical conductivities are plotted as a function of $\Sigma / S$ instead of the pulse number. For all catalysts we found $\sigma$ to be linearly dependent on $\Sigma / S$ provided the degree of reduction remained below 0.1 .

$$
\sigma=\alpha+\beta \cdot \Sigma / S \text {. }
$$

For some catalysts, such as $\mathrm{MoO}_{3}$ and $\mathrm{Bi}_{2} \mathrm{Mo}_{3} \mathrm{O}_{12}$, Eq. (2) could account for all data points. However, for $\mathrm{Bi}_{2} \mathrm{Mo}_{2} \mathrm{O}_{9}$, the electrical conductivity became constant above $\Sigma / S$ around 0.2 although reduction

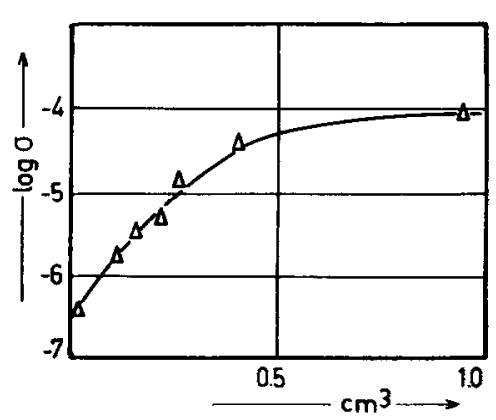

FIG. 17. Relation between the electrical conductivity of the first pulse of butene and the volume of the pulse (in $\mathrm{cm}^{3}$ ) at $T=450^{\circ} \mathrm{C}$ for $\mathrm{Bi}_{2} \mathrm{Mo}_{2} \mathrm{O}_{9}$. 


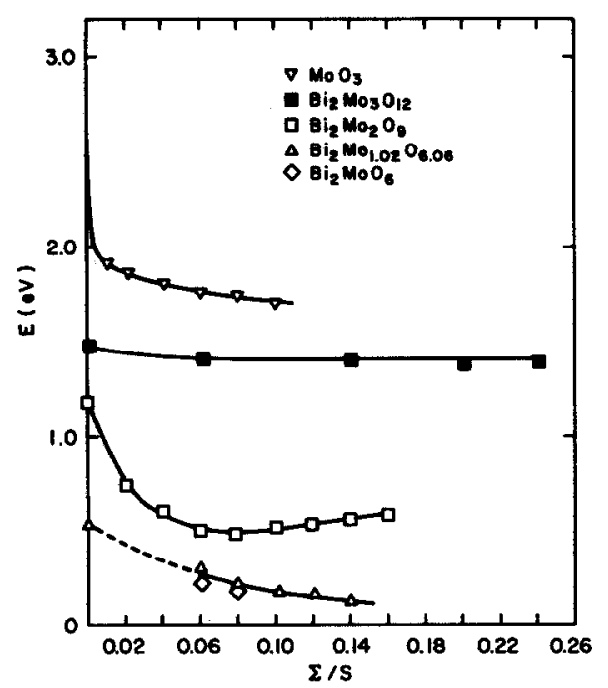

FIG. 18. Dependency of $\varepsilon$ [e.g., Eq. (lb)] on $\Sigma / S$ for various catalysts.

still persisted at an approximately constant level. Similar results were also obtained for the koechlinite samples (see Figs. 8-10). Equation (2) was useful as an interpolation formula for the calculation of the activation energy $\varepsilon$ at a fixed value of $\Sigma / S$ and different temperatures. After insertion in Eq. (1b),

$$
\log \sigma=\log \sigma_{0}-5 \varepsilon \times 1000 / T
$$

where $\sigma$ is expressed in $\Omega^{-1} \mathrm{~cm}^{-1}$, and $\varepsilon$ in $\mathrm{eV}$ we find $\varepsilon$ as a function of $\Sigma / S$.

Proceeding in this manner, we arrived at Fig. 18. The figure shows four curved lines for five catalysts, viz., $\mathrm{MoO}_{3}, \mathrm{Bi}_{2} \mathrm{Mo}_{3} \mathrm{O}_{12}$, $\mathrm{Bi}_{2} \mathrm{Mo}_{2} \mathrm{O}_{9}$, and the overlapping koechlinite (C) and Mo-doped koechlinite (D). The inactive Bi-doped koechlinite $\mathrm{E}$ could be represented by a single point $\varepsilon(0)=0.98$ at $\Sigma / S$ $=0$ [values of $\varepsilon$ at $\Sigma / S=0$ will be further indicated as $\varepsilon(0)]$.

As readily seen, the four lines followed similar patterns. The values of $\varepsilon(0)$ were always highest, i.e., the conductivities were initially low. For four catalysts we found a sharp decrease in $\varepsilon$ between $\Sigma / S=$ 0 and 0.1 after which the $\varepsilon-\Sigma / S$ lines became almost horizontal. However, the line for $\mathrm{Bi}_{2} \mathrm{Mo}_{3} \mathrm{O}_{12}$ was horizontal over the whole range. Numerically, the average $\varepsilon$ values of the four lines were found markedly different; the higher the $\mathrm{Bi} /(\mathrm{Bi}+\mathrm{Mo})$ ratio, the lower $\varepsilon$ and the higher the conductivity. It should be noted that this applied already from the very beginning of the run. The position of the line appeared essentially defined by what happened to the catalyst in the period preceding the introduction of butene, i.e., when the catalyst was heated in $\mathrm{He}$ before being exposed to butene.

The horizontal parts of the lines appear to represent a steady state where oxygen migration from bulk to surface is fast enough to replenish the oxygen depletion caused by the olefin oxidation. Evidently, to prevent the formation of electrical charge differences, oxygen migration should occur simultaneously with a countercurrent electron migration inward.

$$
\text { (Surface) } \underset{\mathrm{O}^{2-}}{\stackrel{2 e^{-}}{\rightleftarrows}} \text { (Bulk). }
$$

Once situated in the bulk, these electrons apparently do not contribute any more to the conductivity, an observation to which we shall return later on.

The observation, that the electrical conductivities of the various catalysts differ considerably over the entire $\Sigma / S$ range can hardly be explained otherwise than by assuming a reversible dissociation of $\mathrm{O}_{2}$ from the catalyst. Indeed, data in Fig. 7 and Table 4 for catalysts $E$ and $D$ show higher values of $\varepsilon$ and therefore lower conductivities when heated in air instead of $\mathrm{He}$; the conductivity decreases with the $\mathrm{O}_{2}$ pressure. It is noteworthy that there is a definite correlation between the average $\varepsilon$ values and the ratios $\mathrm{Bi} /(\mathrm{Bi}+\mathrm{Mo})$; the higher the $\mathrm{Bi}$ content the lower $\varepsilon$ and the higher the conductivity. We therefore postulate that $\mathrm{O}_{2}$ dissociation occurs more readily for surface oxygens bonded to $\mathrm{Bi}$ cations and in particular, will be more facile on $\left(\mathrm{Bi}_{2} \mathrm{O}_{2}\right) \mathrm{O}$ layers. We suggest that a pair of oxygen 
ions donate electrons to a group of trivalent $\mathrm{Bi}$ cations under formation of an oxygen molecule and some $\mathrm{Bi}$ atoms in a stepwise reaction such as shown below:

$$
\left(\mathrm{Bi}^{3+} \mathrm{O}^{2-}\right)_{2} \mathrm{O}^{2-} \rightleftarrows\left(\mathrm{Bi}^{1+} \square\right)_{2} \mathrm{O}^{2-}+\mathrm{O}_{2},
$$

where $\square$ is an oxygen vacancy, followed by a rapid disproportionation

$$
3 \mathrm{Bi}^{+} \rightleftarrows \mathrm{Bi}^{3+}+2 \mathrm{Bi}^{0} \text {. }
$$

It is indeed well established [see, for instance, Batist et al. (8) and Grzybowska et al. (9)] that Bi deposits are formed if koechlinite is heated in vacuum or He at temperatures above $673 \mathrm{~K}$. Evidently, a layer-like structure as koechlinite will be particularly favorably for this reaction although it might also occur on $\mathrm{Bi}_{2} \mathrm{Mo}_{3} \mathrm{O}_{12}$. Since $\mathrm{Bi}$ atoms can be supposed to evaporate from the catalyst this would also explain the striking changes in the surface $\mathrm{Bi} / \mathrm{Mo}$ ratio as found by XPS for catalyst $E$ after activation (see Table 3).

It will be helpful at this place to analyze the activity and selectivity data as obtained in this study; they are summarized in Table 1. The first point of interest is given by a comparison of conversions in continuous flow and pulse operation; for the latter activities we only consider "first pulse" conversions. It is readily seen that the activities in continuous flow are much higher than those in pulse operation. There might be two entirely different explanations for this discrepancy. One of these is directly related to what has been discussed above; since catalysts were already reduced in $\mathrm{He}$ before the first pulse, their activity should be lower because part of the surface sites were still inactive because of previous oxygen losses to the carrier gas. Another explanation can be derived from thermal effects; reactions in continuous flow are exothermic while those in pulse in the absence of oxygen are about thermoneutral. Recent studies by Burban (16) have shown that isothermicity in continuous flow cannot be established for these reactions unless the catalysts are diluted by inert diluents such as $\mathrm{SiC}$ while the reactor is cooled in a fluidized sandbath.

Correct activities will therefore be intermediate between those found in continuous flow and in pulse operation. Another noteworthy observation is given by the dependency of the activity on the $\mathrm{Bi} / \mathrm{Mo}$ ratio. Calculated per gram of catalyst, the conversion was virtually zero for XPS equal to $\mathrm{Bi}$ / $\mathrm{Mo}=2.2$, to become very high around 2. A further decrease in the bulk $\mathrm{Bi} / \mathrm{Mo}$ ratio from 2 to 0.67 caused a proportional decrease of conversion. However, when calculated per unit surface area the conversions remained virtually constant in this range which indicates a constant number of similar sites per unit of surface in the $\mathrm{Bi} / \mathrm{Mo}$ range 2 to 0.67 . Indeed, XPS values for the surface $\mathrm{Bi} / \mathrm{Mo}$ ratio remained approximately constant. Matsuura et al. (7) earlier reported similar conclusions. Since catalyst $\mathrm{E}$ with $\mathrm{a} \mathrm{Bi} / \mathrm{Mo}$ ratio $>2$, was inactive, the impression was gained that a $\mathrm{Bi}$ oxide surface is inactive towards olefins. However, considering the evidence presented in Figs. 15 and 16, this is not entirely correct; catalysts with a $\mathrm{Bi} / \mathrm{Mo}$ ratio around 2 tend to become less selective under extreme circumstances such as high oxygen pressures or temperatures. Figure 15 shows that this may be connected with the formation of a transient $\mathrm{Bi}$-oxygen species during the reoxidation of a partly reduced $\mathrm{Bi}$ oxide surface layer.

Let us now try to qualitatively explain the conductivity data and more in particular the $\varepsilon$ versus $\Sigma / S$ relation. We shall therefore apply band theory with special emphasis on surface band bending (see Fig. 19). As always, the electronic band shall consist of a valence band that is filled, a conduction band that is empty and a band gap between the two. Situated in the band gap are supposed to be two sets of localized energy levels, one near the top of the valence band and the other near the bottom of the conduction band. The first set, if empty, represents $\mathrm{Mo}^{6+}$ cations, the second set $\mathrm{Bi}^{3+}$ cations. 


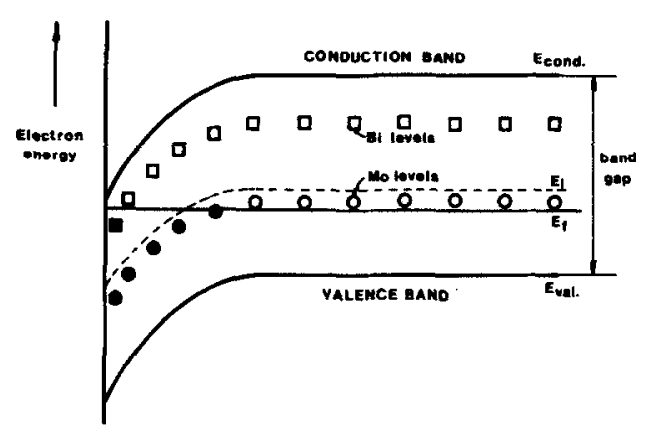

Fig. 19. Model for band structure at surface: $\mathbf{B i}^{3+}$ cation energies $(\square)$, $\mathrm{Mo}^{6+}$ cation energies $(\mathrm{O})$; positions are supposed to be centerlines of distribution of states.

The band model is also supposed to represent $\mathrm{MoO}_{3}$, with only Mo levels present, or $\mathrm{Bi}_{2} \mathrm{O}_{3}$ where only $\mathrm{Bi}$ levels occur. The transition from molybdenum oxide to bismuth oxide via the bismuth molybdates is assumed to be continuous by gradually replacing one Mo by two $\mathrm{Bi}$. This assumption is certainly not appropriate for bulk structures but might be acceptable for surfaces. The literature furnishes some quantitative information on the properties of our surface band. Grzybowska et al. (9) studied the surface band situation of $\mathrm{MoO}_{3}$ by XPS. They found the top of the valence band to be at an energy around $2.8 \mathrm{eV}$. Incipient reduction revealed the presence of two levels in the band gap at 0.9 and $2.0 \mathrm{eV}$; the latter might very well be equivalent to the $\varepsilon$ $=1.8$ level found by us for $\mathrm{MoO}_{3}$; see Fig. 18. According to them these UPS bands belong to $\mathrm{Mo}^{4+}$. Batist et al. (10) used UVVis diffuse reflectance spectroscopy to study the surface band properties of $\mathrm{MoO}_{3}$, $\mathrm{Bi}_{2} \mathrm{Mo}_{2} \mathrm{O}_{9}$, and $\mathrm{Bi}_{2} \mathrm{O}_{3}$. The charge transfer band for $\mathrm{MoO}_{3}$ was found at $2.9 \mathrm{eV}$, hence closely similar to the results of Grzybowska et al. They also noticed a shift of the edge position for $\mathrm{Bi}_{2} \mathrm{Mo}_{2} \mathrm{O}_{9}$ to $2.58 \mathrm{eV}$. Replacement of Mo by $\mathrm{Bi}$ apparently caused a narrowing of the band gap, the reason why $\mathrm{Bi}$ molybdates are bright yellow.

Let us now consider the consequences of this qualitative surface model. Any type of reduction, whether by olefin oxidation or by oxygen dissociation, injects electrons into the surface; these electrons are placed in the localized levels of the band gap. Increasing the reduction shall cause the Fermi level to rise in the band gap thereby diminishing $\varepsilon$. The low-lying Mo levels will be filled first and $\mathrm{Bi}$ levels will be occupied at higher reduction. The conductivity shall increase because the electron density of electrons in the localized levels shall become higher while also the energy difference between Fermi level and conduction band shall diminish.

Consequently, $\sigma$ shall rise and $\varepsilon$ shall decrease. If the localized band system is narrow, the decrease in $\varepsilon$ might be small, but the rise in $\sigma$ remains observable because $\Sigma / S$ increases; see Eq. (2). This behavior is typical for $\mathrm{MoO}_{3}$ and $\mathrm{Bi}_{2} \mathrm{MO}_{3} \mathrm{O}_{12}$. However, for the $\mathrm{Bi}$-rich samples reduction persisted but both $\sigma$ and $\varepsilon$ remained constant. We postulate that this occurs when the Fermi level arrives at an energy coinciding with the lower Mo levels in the bulk. Electrons can now "spill over" from surface to bulk levels. Energetically, the bulk electrons are still far below the bulk conduction band. Since, moreover, the number of levels in the bulk is vastly greater than those in the surface band, the electron density at this particular level remains virtually constant and the surface Fermi level shall become anchored at this position. The inward migration of the electrons shall give rise to an electrical double layer with the positive charge at the surface that also contains the anion vacancies. Oxygen anions shall therefore migrate outward.

Our model provides a chemical explanation for the kinetic "inlet"-"outlet" model of Keulks et al. (11), as based on experiments with oxygen isotopes. The inlet is now identified as an ensemble of $\mathrm{Bi}$ atoms preferably on a partly reduced $\left(\mathrm{Bi}_{2} \mathrm{O}_{2}\right) \mathrm{O}$ layer but not restricted hereto. Similar suggestions were published earlier by Linn and Sleight (13) and by Otsubo et al. (14). As to the outlet, because of the work of Burrington and Grasselli (12), Matsuura et al. 
(7), and Gai (16), there seems to be general agreement about its structure; it is a surface complex containing one $\mathrm{Bi}$ and one $\mathrm{Mo}$, similar to configurations as encountered in $\mathrm{Bi}_{2} \mathrm{Mo}_{2} \mathrm{O}_{9}$. As shown earlier, our results are in reasonable agreement herewith. As far as we know, however, it has never been explained why the inlet-outlet operation is necessary at all. The common Mars-van Krevelen model (M-vK model) assumes that reduction by the hydrocarbon (outlet) occurs at the same place as the reoxidation (inlet).

We want to propose here that the inletoutlet operation is a necessary attribute of selective oxidation because the outlet has to be a single active oxygen in order to maintain selectivity. The inlet, however, has to contain a pair of oxygen vacancies. Inlet and outlet are therefore necessarily different both as to their composition and structural type.

When summarizing our results we conclude that most of the new information produced concerns the clarification of the function of the bismuth component. We showed above that a surface $\left(\mathrm{Bi}_{2} \mathrm{O}_{2}\right) \mathrm{O}$ plane is easily reduced in vacuum or inert gas by dissociation of molecular oxygen, a reaction that is reversible, and therefore directly related to Keulks' inlet site. Another function is connected with the relative inactivity of bismuth oxide versus olefins; at the temperatures applied here it is almost inert in this respect. $\left(\mathrm{Bi}_{2} \mathrm{O}_{2}\right) \mathrm{O}$ layers can therefore partly cover $\left(\mathrm{MoO}_{2}\right) \mathrm{O}$ surfaces and form small Mo-O ensembles even containing only one active oxygen. This guarantees a selective oxidation of olefins but leads to an inhibition of a local reoxidation by molccular oxygen. Note that this is equivalent to an alternative description of the outlet site. Moreover, the facile dissociation of $\mathrm{O}_{2}$ by the $\left(\mathrm{Bi}_{2} \mathrm{O}_{2}\right) \mathrm{O}$ layers and the high mobility of oxygen ions and electrons created thereby ensure a facile oxygen diffusion through the lattice and as a consequence the possibility for the replenishment of oxygen-depleted surface sites.

\section{ACKNOWLEDGMENTS}

The authors thank Professor R. Metselaar for fruitful discussions. They also thank Dr. L. E. Firment for showing his results on the surface science of $\mathrm{MoO}_{3}$ before publication. Peter Burban of the Center for Catalytic Science and Technology at the University of Delaware has to be especially thanked for valuable comments. This work was supported by The Netherlands Foundation of Chemical Research (SON) with financial aid from The Netherlands Foundation for Pure and Scientific Research (ZWO). It formed the subject of part of a Ph.D. thesis by D. A. G. van Oeffelen at the University of Technology, Eindhoven, The Netherlands (17 October 1978).

\section{REFERENCES}

1. Pluta, J., Z. Anorg. Allg. Chem. 356, 105 (1967).

2. Pluta, J., Z. Phys. Chem., Neue Folge 58, 189 (1968).

3. Peacock, J. M., Parker, A. J., Ashmore, P. G., and Hockey, J. A., J. Catal. 15, 387 (1969).

4. Morrison, S. R., ACS preprints 22(2), 485 (1977).

5. Berthou, H., and Jørgensen, C. K., Anal. Chem. 47, 482 (1975).

6. Batist, P. A., Bouwens, J. F. H., and Schuit, G. C. A., J. Catal. 25, 1 (1972).

7. Matsuura, I., Schut, R., and Hirakawa, K., J. Catal. 63, 152 (1980).

8. Batist, P. A., and Lankhuyzen, S. P. P. M., J. Catal. 28, 496 (1973).

9. Grzybowska, B., Haber, J., Marczewski, W., and Ungier, L., J. Catal. 42, 327 (1976).

10. Batist, P. A., der Kinderen, A. H. V. M., Leeuwenburgh, Y., Metz, F. A. M. G., and Schuit, G. C. A., J. Catal. 12, 45 (1968).

11. Keulks, G. W., J. Catal. 19, 232 (1970). Keulks, G. W., and Krenzke, L. D., in "Proceedings, 6th International Congress on Catalysis, London, 1976" (G. C. Bond, P. B. Wells, and F. C. Tomkins, Eds.), p. 806. Chem. Soc., London.

12. Burrington, J. D., and Grasselli, R. K., J. Catal. 59, 79 (1976).

13. Linn, W. J., and Sleight, A. W., Ann. N.Y. Acad. Sci. 272, 22 (1976).

14. Otsubo, T., Miura, H., Morikawa, Y., and Shirakasi, T., J. Catal. 36, 240 (1975).

15. Gai, P. L., in "Fourth International Conference, The Chemistry and Uses of Molybdenum" (H. F. Barry and P. C. H. Mitchell, Eds.), p. 296. 1982.

16. Burban, P. M., Ph.D. Thesis, University of Delaware, Department of Chemical Engineering, Center for Catalytic Science and Technology, 1984. 